\title{
Analisis Kuantitatif Kelengkapan Dokumen Rekam Medis Pasien Rawat Inap Dengan Diagnosa Fracture Femur Di RSUD Dr. R.M. Djoelham Binjai
}

\author{
${ }^{1}$ Giyatno, ${ }^{2}$ Maysyarah Yolla Rizkika \\ Program Studi D-III Perekam Medis dan Informasi Kesehatan, Universitas Imelda Medan
}

\begin{tabular}{l} 
Article Info \\
\hline Article history: \\
Received Feb13, 2020 \\
Revised Feb 25, 2020 \\
Accepted Feb28, 2020 \\
\hline
\end{tabular}

\section{Keywords:}

Quantitative Analysis

Medical Record Documents

Femoral Fracture

\begin{abstract}
ABSTRAK
Medical records officers must carry out quantitative analysis activities to assist doctors in the recording and filling of medical records that are complete and accurate. The purpose of this study was to determine the quantitative analysis of the completeness of inpatient medical record documents with a diagnosis of fracture femur in RSUD DR. R.M. Djoelham Binjai. This type of research is descriptive qualitative. The sample used was the entire population of 36 medical records documents for inpatients with a diagnosis of fracture femur in 2018. Data collection was done using a check list table. The highest completeness of patient identification results is the patient's name, medical record number, and date of birth of 20 documents (56\%), the lowest percentage is gender by 10 medical record documents $(28 \%)$. Completeness of important reporting is general consent of 25 medical record documents (69\%), the lowest percentage is informed consent of 13 medical record documents $(36 \%)$. The highest completeness of authentication was the doctor's signature, the nurse's name and the nurse's signature of 15 medical record documents (42\%), the lowest percentage being the doctor's name and professional title of 11 medical record documents $(31 \%)$. Completeness of correct documentation is the use of abbreviations of 26 medical record documents (72\%), the lowest percentage is error correction of 16 medical record documents (44\%). Completeness of filling medical record documents is not $100 \%$ complete. It is recommended that socialization be needed to all officers related to completeness of filling medical record documents and following the Standard Operating Procedures (SPO) related to quantitative analysis of the completeness of medical record documents.
\end{abstract}

This is an open access article under the CC BY-SAlicense.

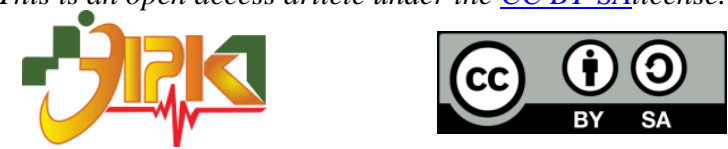

\section{Corresponding Author:}

Giyatno,

Program Studi D-III Perekam Medis dan Informasi Kesehatan,

Universitas Imelda Medan,

Jl. Bilal No. 52 Kelurahan Pulo Brayan Darat I Kecamatan Medan Timur, Medan - Sumatera Utara.

Email: agicida@gmail.com

\section{PENDAHULUAN}

Berdasarkan Undang-Undang RI Nomor 44 Tahun 2009 tentang rumah sakit, rumah sakit adalah intitusi pelayanan kesehatan yang menyelenggarakan pelayanan keesehatan perorangan secara paripurna yang menyediakan pelayanan rawat inap, rawat jalan, dan 
gawat darurat. Terselenggaranya pelayanan kesehatan yang baik tercermin pada kelengkapan dokumen rekam medis yang dibuat (Widjaya, 2018).

Menurut Permenkes Nomor 269/MENKES/PER/III/2008 Pasal 2 ayat 1, rekam medis harus dibuat secara tertulis, lengkap, dan jelas atau secara elektronik. Jelas bagi kita bahwa rekam medis wajib dibuat lengkap oleh pemberi pelayanan baik dengan menggunakan kertas ataupun elektronik. Berdasarkan Permenkes Nomor 269/MENKES/PER/III/2008 Pasal 5 ayat 2 , rekam medis harus dibuat segera dan dilengkapi setelah pasien menerima pelayanan. Pembuatan rekam medis sebagaimana dimaksud pada ayat (2) dilaksanakan melalui pencatatan dan pendokumentasian hasil pemeriksaan, pengobatan, tindakan, dan pelayanan lain yang telah diberikan kepada pasien.

Analisis kuantitatif adalah telaah atau review bagian tertentu dari isi rekam medis dengan maksud menemukan kekurangan khusus dari isi rekam medis dengan maksud menemukan kekurangan khusus yang berkaitan dengan pendokumentasian rekam medis (Edy dan Sugiarto, 2017). Analisis kuantitatif terdiri dari 4 (empat) komponen yaitu review identifikasi, review laporan yang penting, review autentikasi dan review pendokumentasian yang benar (Widjaya, 2018). Petugas rekam medis harus melakukan kegiatan analisa kuantitatif guna membantu dokter dalam kegiatan pencatatan dan pengisian rekam medis yang lengkap dan akurat (Edy dan Sugiarto, 2017).

Berdasarkan penelitian sebelumnya oleh Duwi dan Dyah tahun 2015, dari 64 dokumen rekam medis rawat inap pada pasien dengue haemorrhagic fever yang diteliti angka ketidaklengkapan dalam pengisian berkas paling tinggi terdapat pada formulir RM 3, RM 5, RM 6B, RM 7, RM 7A, RM 9C, RM 13 dan visite dokter yaitu 100\% tidak lengkap. Dampak dari masalah yang terjadi apabila dokumen rekam medis tidak lengkap adalah kualitas data yang dihasilkan tidak baik dan tidak akurat sehingga dapat merugikan manajemen rumah sakit sendiri dalam pengambilan keputusan. Oleh karena itu, rekam medis sangat penting keberadaannya bagi pelayanan kesehatan.

Berdasarkan pengamatan pada saat survey awal di RSUD DR R.M Djoelham Binjai, dokumen rekam medis pasien dengan penyakit fracture femur tahun 2018 terdapat ketidaklengkapan pengisian dokumen rekam medis. Dari survey awal dengan pengambilan data 10 dokumen rekam medis pasien fracture femur yang sudah pulang (retrospektif analysis) terdapat 9 dokumen (90\%) yang terisi tidak lengkap pada review identifikasi pasien yaitu jenis kelamin. Pada review pelaporan penting yaitu resume medis dan informed consent terdapat 8 dokumen (80\%) yang terisi tidak lengkap. Pada review autentifikasi yaitu nama perawat, tanda tangan perawat, dan gelar profesional terdapat 10 dokumen $(100 \%)$ yang terisi tidak lengkap, sedangkan pada review pendokumentasian yang benar yaitu bagian kosong terdapat 10 dokumen (100\%). Berdasarkan latar belakang permasalahan diatas, peneliti tertarik melakukan penelitian dengan judul "Analisis Kuantitatif Kelengkapan Dokumen Rekam Medis Pasien Rawat Inap Dengan Diagnosa Fracture Femur di RSUD DR. R.M Djoelham Binjai".

Penelitian sebelumnya yang berkaitan dengan ketidaklengkapan dokumen rekam medis menyatakan agar petugas melengkapi ketidaklengkapan dokumen rekam medis pada pasien (Simanjuntak \& Napitupulu, 2019).

\section{METODE PENELITIAN}

A. Jenis Penelitian

Jenis penelitian yang digunakan adalah penelitian deskriptif kualitatif yang bertujuan untuk mengidentifikasi kelengkapan dokumen rekam medis pasien rawat inap dengan diagnosa fracture femur di RSUD Dr. R.M. Djoelham Binjai. Pengambilan data yang dilakukan adalah dengan menggunakan metode observasi yaitu dengan melihat dan mencatat hal tertentu yang ada hubunganya dengan masalah. Penelitian 
ini dilaksanakan pada bulan Februari s/d April 2019. Penelitian ini dilaksanakan di RSUD Dr. R.M. Djoelham Binjai yang beralamat di Jalan Sultan Hasanuddin No. 9 Binjai.

B. Sampel

Menurut Arikunto tahun 2010 jika jumlah populasinya kurang dari 100, maka jumlah sampelnya diambil secara keseluruhan, tetapi jika populasinya lebih besar dari 100, maka bisa diambil $10-15 \%$ atau 20-25\% dari jumlah populasinya. Berdasarkan penelitian ini karena jumlah populasinya tidak lebih besar dari 100, maka sampel yang digunakan adalah seluruh jumlah populasi yaitu 36 dokumen rekam medis pasien rawat inap dengan diagnosa fracture femur di RSUD Dr. R.M. Djoelham Binjai pada tahun 2018.

C. Populasi

Populasi adalah keseluruhan objek penelitian (Noor J, 2017). Populasi dalam penelitian ini adalah seluruh dokumen rekam medis pasien rawat inap dengan diagnosa fracture femur di RSUD Dr. R.M. Djoelham Binjai pada tahun 2018 yang berjumlah 36 dokumen rekam medis.

D. Variabel Penelitian

Variabel pada penelitian ini adalah:

1. Review Identifikasi Pasien

2. Review Pelaporan Penting

3. Review Autentifikasi

4. Review Pendokumentasian yang Benar.

E. Defenisi Operasional

Tabel 1. Defenisi Operasional

\begin{tabular}{|c|c|c|}
\hline No & Variabel & Defenisi Oper \\
\hline 1 & $\begin{array}{l}\text { Review Identifikasi } \\
\text { Pasien }\end{array}$ & $\begin{array}{l}\text { Memastikan kelengkapan pada pengisisan identitas } \\
\text { jika seluruh item sudah terisi, nomor rekam medis, } \\
\text { nama pasien, tanggal Lahir, jenis kelamin. }\end{array}$ \\
\hline 2 & $\begin{array}{l}\text { Revi } \\
\text { Penti }\end{array}$ & $\begin{array}{l}\text { Memastikan kelengkapan pada pengkajian awal, } \\
\text { general consent, resume medis, informed consent, } \\
\text { laporan anastesi, laporan operasi. }\end{array}$ \\
\hline 3 & $\begin{array}{l}\text { Revie } \\
\text { Auten }\end{array}$ & $\begin{array}{l}\text { Memastikan kelengkapan keabsahan rekaman } \\
\text { autentifikasi jika terdapat, nama dokter atau stempel, } \\
\text { tanda tangan dokter, nama perawat, tanda tangan } \\
\text { perawat, gelar professional }\end{array}$ \\
\hline 4 & $\begin{array}{l}\text { Review } \\
\text { Pendokumentasian } \\
\text { Yang Benar }\end{array}$ & $\begin{array}{l}\text { Memastikan pendokumentasian yang benar jika } \\
\text { pencatatan jelas dan terbaca, penggunaan singkatan, } \\
\text { pembetulan kesalahan penulisan, bila ada baris yang } \\
\text { kosong diberi tanda }\end{array}$ \\
\hline
\end{tabular}

F. Intrumen Penelitian

Instrumen penelitian adalah alat bantu yang di pilih dan digunakan oleh peneliti dalam kegiatannya mengumpulkan data agar kegiatan tersebut menjadi sistematis dan dipermudah olehnya (Arikunto, 2010). Di dalam penelitian ini instrumen penelitian yang digunakan adalah tabel check list.

G. Cara Pengumpulan Data

Adapun cara pengumpulan data pada penelitian ini yaitu:

1. Data Primer 
Pengumpulan data dilakukan dengan menggunakan tabel check list untuk melihat kelengkapan dokumen rekam medis pasien rawat inap dengan diagnosa fracture femur di RSUD Dr. R.M. Djoelham Binjai pada tahun 2018.

2. Data Sekunder

Pengumpulan data sekunder dengan indeks penyakit untuk mengetahui populasi penyakit fracture femur pada tahun 2018.

H. Teknik Pengolahan

Adapun teknik pengolahan data pada penelitian ini yaitu:

1. Editing

Yaitu melakukan koreksi kembali hasil pengumpulan data pada check list untuk menghindari data yang tidak terbaca atau salah tulis.

2. Tabulasi

Data yang telah dikelompokan sesuai dengan kategorinya kemudian dikelompokan pada tebel untuk memudahkan dalam analisa data.

3. Penyajian Data

Menyajikan data dalam bentuk narasi dan tabel.

I. Analisis Data

Analisa data digunakan untuk menyederhanakan data kedalam bentuk yang lebih mudah dibaca dan dimengerti. Analisa data dilakukan secara deskriptif dengan melihat presentasi data yang telah terkumpul disajikan dalam tabel distribusi frekuensi sesuai dengan kategori data yang sudah dikelompokkan kemudian dilanjutkan dengan membahas hasil penelitian dengan menggunakan teori kepustakaan yang ada dan dapat diperoleh suatu kesimpulan.

\section{HASIL DAN PEMBAHASAN}

\subsection{Hasil}

Tabel 2. Distribusi Frekuensi Kelengkapan Pengisisan Komponen Identifikasi Pasien Pada Pasien Rawat Inap Diagnosa Fracture Femur

\begin{tabular}{|c|c|c|c|c|c|c|c|}
\hline \multirow{4}{*}{ No } & \multirow{4}{*}{ Nama Item } & \multirow{2}{*}{\multicolumn{4}{|c|}{ Persentase Item Kelengkapan Identifikasi }} & \multirow{3}{*}{\multicolumn{2}{|c|}{ Jumlah }} \\
\hline & & & & & & & \\
\hline & & \multicolumn{2}{|c|}{ Terisi Lengkap } & \multicolumn{2}{|c|}{ Tidak Terisi Lengkap } & & \\
\hline & & f & $\%$ & $f$ & $\%$ & f & $\%$ \\
\hline 1 & Nama Pasien & 20 & 56 & 16 & 44 & 36 & 100 \\
\hline 2 & $\begin{array}{l}\text { Nomor Rekam } \\
\text { Medis }\end{array}$ & 20 & 56 & 16 & 44 & 36 & 100 \\
\hline 3 & Tanggal Lahir & 20 & 56 & 16 & 44 & 36 & 100 \\
\hline 4 & Jenis Kelamin & 10 & 28 & 26 & 72 & 36 & 100 \\
\hline
\end{tabular}

Berdasarkan tabel 2 diketahui bahwa persentase tertinggi kelengkapan pengisian komponen identifikasi pasien pada pasien rawat inap diagnosa fracture femur yaitu terdapat pada item nama pasien sebesar 20 dokumen rekam medis (56\%), nomor rekam medis sebesar 20 dokumen rekam medis (56\%) yang terisi lengkap, dan tanggal lahir sebesar 20 dokumen rekam medis $(56 \%)$ yang terisi lengkap. Persentase terendah terdapat pada item jenis kelamin sebesar 10 dokumen rekam medis (28\%) yang terisi lengkap.

Tabel 3. Distribusi Frekuensi Kelengkapan Pengisian Komponen Pelaporan Penting Pada Pasien Rawat Inap Diagnosa Fracture Femur

\begin{tabular}{|c|c|c|c|c|}
\hline \multirow{3}{*}{ No } & \multirow{3}{*}{ Nama Item } & \multicolumn{2}{|c|}{$\begin{array}{l}\text { Persentase Item Kelengkapan } \\
\text { Pelaporan Penting } \\
\end{array}$} & \multirow{2}{*}{ Jumlah } \\
\hline & & Terisi Lengkap & $\begin{array}{c}\text { Tidak Terisi } \\
\text { Lengkap }\end{array}$ & \\
\hline & & $\%$ & $\%$ & $\%$ \\
\hline
\end{tabular}

Analisis Kuantitatif Kelengkapan Dokumen ... (Giyatno) 


\begin{tabular}{llllllll}
\hline 1 & Pengkajian Awal & 17 & 47 & 19 & 53 & 36 & 100 \\
\hline 2 & General Consent & 25 & 69 & 11 & 31 & 36 & 100 \\
\hline 3 & Resume Medis & 19 & 53 & 17 & 47 & 36 & 100 \\
\hline 4 & Informed Consent & 13 & 36 & 23 & 64 & 36 & 100 \\
\hline 5 & Laporan Anastesi & 20 & 56 & 16 & 44 & 36 & 100 \\
\hline 6 & Laporan Operasi & 18 & 50 & 18 & 50 & 36 & 100 \\
\hline
\end{tabular}

Berdasarkan tabel 3 diketahui bahwa persentase tertinggi kelengkapan pengisian komponen pelaporan penting pada pasien rawat inap diagnosa fracture femur yaitu terdapat pada item general consent sebesar 25 dokumen rekam medis (69\%) yang terisi lengkap. Persentase terendah terdapat pada item informed consent sebesar 13 dokumen rekam medis (36\%) yang terisi lengkap.

Tabel 4. Distribusi Frekuensi Kelengkapan Pengisian Komponen Autentifikasi Pada Pasien Rawat Inap Diagnosa Fracture Femur

\begin{tabular}{|c|c|c|c|c|c|c|c|}
\hline \multirow{3}{*}{ No } & \multirow{3}{*}{ Nama Item } & \multicolumn{4}{|c|}{$\begin{array}{c}\text { Persentase Item Kelengkapan } \\
\text { Autentifikasi }\end{array}$} & \multirow{2}{*}{\multicolumn{2}{|c|}{ Jumlah }} \\
\hline & & \multicolumn{2}{|c|}{ Terisi Lengkap } & \multicolumn{2}{|c|}{$\begin{array}{l}\text { Tidak Terisi } \\
\text { Lengkap }\end{array}$} & & \\
\hline & & $f$ & $\%$ & $\mathrm{f}$ & $\%$ & $f$ & $\%$ \\
\hline 1 & Nama Dokter & 11 & 31 & 25 & 69 & 36 & 100 \\
\hline 2 & Tanda Tangan Dokter & 15 & 42 & 21 & 58 & 36 & 100 \\
\hline 3 & Nama Perawat & 15 & 42 & 21 & 58 & 36 & 100 \\
\hline 4 & Tanda Tangan Perawat & 15 & 42 & 21 & 58 & 36 & 100 \\
\hline 5 & Gelar Profesional & 11 & 31 & 25 & 69 & 36 & 100 \\
\hline
\end{tabular}

Berdasarkan tabel 4 diketahui bahwa persentase tertinggi kelengkapan pengisian komponen autentifikasi pada pasien rawat inap diagnosa fracture femur yaitu terdapat pada item tanda tangan dokter sebesar 15 dokumen rekam medis (42\%) yang terisi lengkap, nama perawat sebesar 15 dokumen rekam medis (42\%) yang terisi lengkap, dan tanda tangan perawat sebesar 15 dokumen rekam medis $(42 \%)$ yang terisi lengkap. Persentase terendah terdapat pada item nama dokter 11 dokumen rekam medis (31\%) yang terisi lengkap dan gelar profesional sebesar 11 dokumen rekam medis (31\%) yang terisi lengkap.

Tabel 5. Distribusi Frekuensi Kelengkapan Pengisian Komponen Pendokumentasian Yang Benar Pada Pasien Rawat Inap Diagnosa Fracture Femur

\begin{tabular}{llcccccc}
\hline \multirow{2}{*}{ No } & \multirow{3}{*}{ Nama Item } & \multicolumn{3}{c}{$\begin{array}{c}\text { Persentase Item Kelengkapan } \\
\text { Identifikasi Pasien }\end{array}$} & \multirow{2}{*}{ Jumlah } \\
\cline { 3 - 7 } & & Terisi Lengkap & \multicolumn{2}{c}{$\begin{array}{c}\text { Tidak Terisi } \\
\text { Lengkap }\end{array}$} & & \\
\cline { 3 - 7 } & & $\mathrm{f}$ & $\%$ & $\mathrm{f}$ & $\%$ & $\mathrm{f}$ & $\%$ \\
\hline 1 & Jelas Terbaca & 25 & 69 & 11 & 31 & 36 & 100 \\
\hline 2 & Penggunaan Singkatan & 26 & 72 & 10 & 28 & 36 & 100 \\
\hline 3 & Pembetulan Kesalahan & 16 & 44 & 20 & 56 & 36 & 100 \\
\hline 4 & Bagian Kosong & 17 & 47 & 19 & 53 & 36 & 100 \\
\hline
\end{tabular}

Berdasarkan tabel 5 diketahui bahwa persentase tertinggi kelengkapan pengisian komponen pendokumentasian yang benar pada pasien rawat inap diagnosa fracture femur yaitu terdapat pada item penggunaan singkatan sebesar 26 dokumen rekam medis (72\%) yang baik. Persentase terendah terdapat pada item pembetulan kesalahan sebesar 16 dokumen rekam medis (44\%) yang baik.

Incomplete Medical Record (IMR) 
IMR : Jumlah Rekam Medis Tidak Lengkap $\quad$ x 100\%

Jumlah Rekam Medis Yang Di Terima

IMR : $36 \times 100 \%=100 \%$

36

Jadi persentase ketidaklengkapan dokumen rekam medis fracture femur sebesar 100\%.

\subsection{Pembahasan}

Berdasarkan hasil penelitian diketahui bahwa persentase tertinggi kelengkapan pengisian komponen identifikasi pasien pada pasien rawat inap diagnosa fracture femur yaitu terdapat pada item nama pasien, nomor rekam medis, dan tanggal lahir sebesar 20 dokumen rekam medis (56\%) yang terisi lengkap. Persentase terendah terdapat pada item jenis kelamin sebesar 10 dokumen rekam medis (28\%) yang terisi lengkap.

Kelengkapan pengisian komponen identifikasi pasien bertujuan untuk memastikan pemilik dari dokumen rekam medis tersebut. Kelengkapan identifikasi pasien pada dokumen rekam medis merupakan data administratif sebagai informasi demografi harus terisi lengkap karena jika tidak terisi lengkap berakibat tidak dapat menginformasikan identitas pasien sebagai basis data statistik, riset dan sumber perencanaan rumah sakit atau pelayanan kesehatan.

Hal ini sejalan dengan penelitian yang dilakukan Elvisa tahun 2017, menunjukan bahwa persentase tertinggi kelengkapan pengisian komponen identisikasi pasien terdapat pada item nama pasien sebesar $92 \%$ yang terisi lengkap sedangkan persentase terendah terdapat pada item jenis kelamin sebesar $52 \%$ yang terisi lengkap.

Setiap formulir rekam medis minimal harus memiliki identitas pasien seperti nama pasien, nomor rekam medis, tanggal lahir, dan jenis kelamin. Bila ada lembaran yang tanpa identitas harus di review untuk menentukan milik siapa lembaran tersebut (Widjaya, 2018). Dokumen rekam medis dikatakan lengkap apabila semua data yang ada didalamnya terisi lengkap dan benar sesuai ketentuan yang telah ditetapkan di rumah sakit (Hatta, 2013).

Kelengkapan pengisian pada komponen identifikasi pasien pada pasien rawat inap diagnosa fracture femur di RSUD Dr. R.M Djoelham Binjai belum lengkap 100\% dikarenakan banyaknya formulir rekam medis yang harus dilengkapi dimana setiap formulir harus diisi dengan identitas sehingga masih ada yang terlewatkan tidak dilengkapi atau ditulis oleh petugas yang bertanggung jawab serta keterbatasan barcode yang digunakan untuk menempel identitas pada formulir tersebut.

Hal ini belum sesuai dengan Standar Prosedur Operasional (SPO) RSUD Dr. R.M Djoelham Binjai Nomor III/RM/SPO/445-956/IX/16 tentang pengisian berkas rekam medis pasien tahun 2016, dimana rekam medis harus diisi dengan lengkap. Dan juga belum sesuai dengan Keputusan Menteri Kesehatan No.129/MENKES/SK/II/2008 tentang Standar Pelayanan Minimal (SPM) Rumah Sakit dimana standar pelayanan rekam medis rumah sakit yaitu kelengkapan pengisian rekam medis 24 jam setelah selesai pelayanan.

\section{Kelengkapan Pengisian Komponen Pelaporan Penting}

Berdasarkan hasil penelitian diketahui bahwa persentase tertinggi kelengkapan pengisian komponen pelaporan penting pada pasien rawat inap diagnosa fracture femur yaitu terdapat pada item general consent sebesar 25 dokumen rekam medis (69\%) yang terisi lengkap. Persentase terendah terdapat pada item informed consent sebesar 13 dokumen rekam medis (36\%) yang terisi lengkap. Hal ini terjadi karena formulir pada dokumen rekam medis yang banyak, sehingga sering terlewatkan beberapa lembar dan item yang tidak terisi oleh dokter yang bertanggung jawab. Selain itu terjadi karena keterbatasan waktu dokter, sehingga waktu yang digunakan untuk mengisi dokumen rekam medis sangat terbatas.

Menurut penelitian Elvisa tahun 2017, persentase yang terendah kelengkapan pengisian komponen pelaporan penting terdapat pada item riwayat penyakit sebesar $76 \%$. Hal ini 
terjadi karena formulir pada rekam medis yang banyak, sehingga sering terlewatkan beberapa lembar dan item yang tidak terisi oleh dokter yang bertanggung jawab. Selain itu terjadi karena keterbatasan waktu dokter, dimana dokter sudah mengisi diagnosa pada formulir yang lain seperti pada formulir terintegrasi dan pada formulir ringkasan masuk dan keluar, sehingga pada formulir resume medis sering terlewatkan dan tidak lengkap.

Setiap hal yang didapatkan dari pasien harus dilaporkan (tercantum) dalam rekam medis seperti, pengkajian awal, general consent, resume medis, informed consent, laporan anastesi, laporan operasi (Widjaya, 2018). Rekam medis sangat bernilai penting karena jika terdapat diagnosa yang tidak benar ataupun tidak lengkap maka secara otomatis kode penyakitnya pun tidak tepat, hal tersebut dapat mempengaruhi terhadap pengisian indeks penyakit dan laporan rumah sakit (Depkes RI, 2006).

Dalam pengisian komponen pelaporan penting haruslah diperhatikan kelengkapannya, karena suatu bukti tertulis dalam mendukung aspek hukum rekam medis, hal ini untuk melindungi pasien atas setiap tindakan yang dilakukan tidak dikategorikan sebagai malpraktek. Apabila tidak terisi lengkap dapat mengakibatkan kerugian bagi pasien, baik itu material maupun nonmaterial maka akan dikenai sanksi administrasi (Permenkes, 2008).

Kelengkapan pengisian komponen pelaporan penting pada pasien rawat inap diagnosa fracture femur di RSUD Dr. R.M Djoelham Binjai belum lengkap 100\%. Hal ini belum sesuai dengan Standar Prosedur Operasional (SPO) RSUD Dr. R.M Djoelham Binjai Nomor III/RM/SPO/445-956/IX/16 tentang pengisian berkas rekam medis, bahwa isi informed consent harus lengkap, tertulis tentang penyakitnya.

\section{Kelengkapan Pengisian Komponen Autentifikasi}

Mengacu pada Peraturan Menteri Kesehatan Nomor 269 / MENKES / PER / III/2008 pada pasal 5 ayat 4, setiap pencatatan dalam rekam medis harus dibubuhi nama, waktu dan tanda tangan dokter, dokter gigi atau tenaga kesehatan tertentu yang memberikan pelayanan kesehatan secara langsung. Dalam pengisian rekam medis setiap isian harus jelas penanggung jawabnya. Review autentifikasi dapat berupa nama atau cap (stempel), tanda tangan, gelar profesional (Widjaya, 2018).

Berdasarkan hasil penelitian diketahui bahwa persentase tertinggi kelengkapan pengisian komponen autentifikasi pada pasien rawat inap diagnosa fracture femur yaitu terdapat pada item tanda tangan dokter, nama perawat dan tanda tangan perawat sebesar 15 dokumen rekam medis (42\%) yang terisi lengkap. Persentase terendah terdapat pada item nama dokter dan gelar profesional sebesar 11 dokumen rekam medis (31\%) yang terisi lengkap. Hasil tersebut menunjukan bahwa masih banyak nama dokter dan gelar profesional yang belum terisi lengkap pada dokumen rekam medis. Hal tersebut dikarenakan kesibukan dokter untuk menulis autentifikasi, sehingga dokter lebih sering untuk tanda tangan saja. Hal ini dapat mengakibatkan pemeriksaan, perawatan maupun pengobatan yang telah dilakukan tidak bias dipertanggung jawabkan oleh dokter tersebut dan dapat mempersulit petugas dalam menentukan dokter yang bertanggung jawab terhadap pasien.

Sejalan dengan hasil penelitian Nurliani tahun 2015, menunjukan bahwa persentase terendah kelengkapan pengisian komponen autentifikasi terdapat pada item nama dokter sebesar 18 dokumen rekam medis $(47,4 \%)$ yang terisi lengkap. Hal ini terjadi karena kesibukan dokter, sehingga dokter sering untuk tanda tangan saja dan bagian identitas berupa nama bias dilengkapi oleh petugas kesehatan lain.

Kelengkapan pengisian komponen autentifikasi sangat penting bagi pihak rumah sakit. Seharusnya dokter dan petugas kesehatan lainnya bekerja sama agar autentifikasi pada dokumen rekam medis terisi lengkap. Kelengkapan komponen autentifikasi pada pasien rawat inap diagnosa fracture femur di RSUD Dr. R.M Djoelham Binjai belum lengkap 100\%. Hal ini belum sesuai dengan Standar Prosedur Operasional (SPO) RSUD Dr. R.M 
Djoelham Binjai Nomor III/RM/SPO/445-956/IX/16 tentang pengisian berkas rekam medis, dimana isi rekam medis harus diisi dengan lengkap dan semua catatan disahkan dengan dibubuhi tanda tangan dan nama terang pencatat, tanggal dan jam watu mencatat.

\section{Kelengkapan Pengisian Komponen Pendokumentasian Yang Benar}

Berdasarkan hasil penelitian diketahui persentase tertinggi kelengkapan pengisian komponen pendokumentasian yang benar pada pasien rawat inap diagnosa fracture femur yaitu terdapat pada item penggunaan singkatan sebesar 26 dokumen rekam medis (72\%) yang baik. Persentase terendah terdapat pada item pembetulan kesalahan sebesar 16 dokumen rekam medis (44\%) yang baik. Hal ini terjadi karena dokter ataupun perawat mencoret pada tulisan yang salah beberapa kali dan tidak membubuhi tanda tangan. Dalam pembetulan kesalahan petugas juga sering menggunakan stipo (dihapus dengan tip ex).

Kesalahan dalam pembetulan kesalahan disebabkan karena petugas yang kadang terburu-buru sehingga menyebabkan kesalahan dalam pembetulan kesalahan. Kesalahan dalam pembetulan tulisan dapat membuat data yang ditulis menjadi tidak sah atau benar untuk dijadikan bukti tindakan yang telah dokter lakukan kepada pasien. Sejalan dengan hasil penelitian Elvisa tahun 2017, menunjukan bahwa pada item pembetulan kesalahan belum dicoret dan dibubuhi tanda tangan. Apabila ada kesalahan tulisan ditumpuk tanpa coretan selain itu tulisan dokter yang sering menulis pada baris yang tidak sesuai, dan susah terbaca menyulitkan petugas rekam medis untuk melakukan koding pada diagnosa maupun tindakan pada berkas rekam medis pasien.

Menurut Permenkes Nomor 269/MENKES/PER/III/2008 pada pasal 5, ayat 5, dalam hal terjadi kesalahan dalam melakukan pencatatan pada rekam medis dapat dilakukan pembetulan dengan cara pencoretan tanpa menghilangkan catatan yang dibetulkan dan dibubuhi paraf dokter, dokter gigi atau tenaga kesehatan tertentu yang bersangkutan.

Kelengkapan pengisian komponen pendokumentasian yang benar pada pasien rawat inap diagnosa fracture femur di RSUD Dr. R.M Djoelham Binjai belum lengkap 100\%, dimana item pembetulan kesalahan berada di persentase terendah. Hal ini belum sesuai dengan Standar Prosedur Operasional (SPO) RSUD Dr. R.M Djoelham Binjai Nomor III/RM/SPO/445-956/IX/16 tentang pengisian berkas rekam medis, bahwa pembetulan kesalahan tidak diperkenankan untuk di stipo (dihapus dengan tip ex) dan kalimat koreksi atau ada tambahan harus diparaf dan nama terang pengkoreksi serta diberi tanggal dan jam.

\section{KESIMPULAN}

Berdasarkan hasil penelitian yang berjudul "Analisa Kuantitatif Kelengkapan Dokumen Rekam Medis Pasien Rawat Inap Dengan Diagnosa Fracture Femur di RSUD Dr. R.M Djoelham Binjai" dari 36 sampel, kelengkapan pengisian dokumen rekam medis belum lengkap $100 \%$ dan dapat disimpulkan sebagai berikut:

1. Persentase tertinggi kelengkapan pengisian komponen identifikasi pasien pada pasien rawat inap diagnosa fracture femur yaitu terdapat pada item nama pasien, nomor rekam medis, dan tanggal lahir sebesar 20 dokumen rekam medis (56\%) yang terisi lengkap. Persentase terendah terdapat pada item jenis kelamin sebesar 10 dokumen rekam medis $(28 \%)$ yang terisi lengkap.

2. Persentase tertinggi kelengkapan pengisian komponen pelaporan penting pada pasien rawat inap diagnosa fracture femur yaitu terdapat pada item general consent sebesar 25 dokumen rekam medis (69\%) yang terisi lengkap. Persentase terendah terdapat pada item informed consent sebesar 13 dokumen rekam medis (36\%) yang terisi lengkap. 
3. Persentase tertinggi kelengkapan pengisian komponen autentifikasi pada pasien rawat inap diagnosa fracture femur yaitu terdapat pada item tanda tangan dokter, nama perawat dan tanda tangan perawat sebesar 15 dokumen rekam medis $(42 \%)$ yang terisi lengkap. Persentase terendah terdapat pada item nama dokter dan gelar profesional sebesar 11 dokumen rekam medis (31\%) yang terisi lengkap.

4. Persentase tertinggi kelengkapan pengisian komponen pendokumentasian yang benar pada pasien rawat inap diagnosa fracture femur yaitu terdapat pada item penggunaan singkatan sebesar 26 dokumen rekam medis (72\%) yang baik. Persentase terendah terdapat pada item pembetulan kesalahan sebesar 16 dokumen rekam medis (44\%) yang baik.

\section{REFERENCES}

Arikunto, S. 2010. Prosedur Penelitian Suatu Pendekatan Praktik. Jakarta: Rineka Cipta.

Depkes RI. 1995. Surat Edaran Dirjen Yanmed No. HK 00.06.1.5.0.1160 Tentang Petunjuk Teknis Pengadaan Formulir Rekam Medis dan Pemusnahan Arsip Rekam Medis di Rumah Sakit. Jakarta: Depkes RI.

Depkes RI. 2006. Pedoman Pengelolahan Dokumen Rekam Medis Rumah Sakit Di Indonesia. Jakarta: Direktorat Jendral Pelayanan Rekam Medik.

Edi, Susanto dan Sugiarto. 2017. Manajemen Informasi Kesehatan IV Etika Profesi dan Hukum Kedehatan. Jakarta: Kemenkes RI.

Elvisa, Nugraheni. 2017. Studi Analisis Kelengkapan Pengisian Formulir Resume Medis Pada Rekam Medis Rawat Inap Pasien JKN Di Rumah Sakit Ortopedi Prof Dr. R. Soeharso Surakarta. Surakarta: Fakultas Ilmu Kesehatan UMS.

Hatta, G. 2013. Pedoman Manajemen Informasi Kesehatan di Saranan Pelayanan Kesehatan. Jakarta: UI-Press

Kementerian Kesehatan Republik Indonesia. 2004. Undang - Undang No. 29 Tahun 2004. Tentang Praktik Kedokteran. Jakarta: Kemenkes RI.

.2008. No.129/MENKES/SK/II/2008 Tentang Standar Pelayanan Minimal (SPM). Jakarta: Kemenkes RI.

. 2008. Peraturan Menteri Kesehatan RI No 269/MENKES/PER/III/2008 Tentang Rekam Medis. Jakarta: Kemenkes RI.

. 2009. Undang - Undang No.44 Tahun 2009. Tentang Rumah Sakit. Jakarta: Kemenkes RI.

Lidia, Duwi dan Ernawati, Dyah. 2015. Analisis Kuantitatif dan Kualitatif Dokumen Rekam Medis Rawat Inap Pada Pasien Dengue Haemorrhagic Fever Di Rumah Sakit Permata Medika Semarang Periode Triwulan I Tahun 2015. Semarang: Fakultas Ilmu kesehatan UDINUS.

Mathar, Irmawati. 2018. Manajemen Informasi Kesehatan Pengolahan Dokumen Rekam Medis. Yogyakarta: Deepublish. 
Muttaqin, Arif. 2012. Asuhan Keperawatan Klien. Jakarta: Salemba Medika.

Noor, J. 2017. Metode Penelitian. Jakarta: Kencana.

Nurlaini, Ajeng. 2015. Analisis Kuantitatif Kelengkapan Dokumen Rekam Medis Rawat Inap Formulir Ringkasan Masuk dan Keluar Periode Triwulan IV Tahun 2015. Bandung: APIKES Bandung.

Rano, Indradi. 2017. Rekam Medis. Tanggerang: Universitas Terbuka.

Rustiyanto, Ery. 2009. Etika Profesi Perekam Medis Informasi Kesehatan. Yogyakarta: Graha Ilmu.

Simanjuntak, E., \& Napitupulu, B. (2019). Analisis Ketidaklengkapan Dokumen Rekam Medis Menurut Standar Akreditasi Rumah Sakit Mki 19.1 Versi Kars 2012 Di Rumah Sakit Umum Imelda Pekerja Indonesia (Rsu Ipi) Medan Tahun 2018. Jurnal Ilmiah Perekam Dan Informasi Kesehatan, 4(1), 533-536. http://ojs.stikesimelda.ac.id/index.php/jipdik/article/view/306.

Sjamsuhidajat. 2009. Buku Ajar Ilmu Bedah. Jakarta: EGC.

Wahid, Abdul. 2013. Keperawatan Medikal Bedah. Jakarta: CV Trans Info Media.

Wijaya, Lily dan Rosmala, Deasy. 2017. Manajemen Informasi Kesehatan II: Sistem dan Subsistem Pelayanan RMIK. Jakarta: Kemenkes RI

\section{BIOGRAPHIES OF AUTHORS}

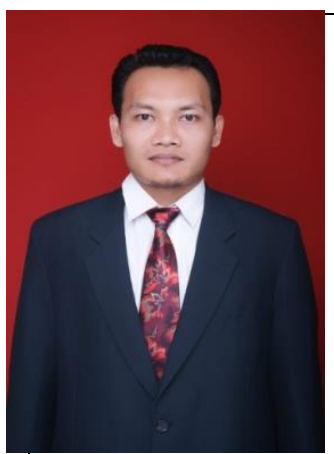

Giyatno, Gelar Ahli madya perekam medis dan informasi kesehatan diperoleh dari APIKES Bhakti Mulia pada Tahun 2005. Sarjana Komputer diperoleh dari Universitas Panca Budi Jurusan Teknik Informasi pada Tahun 2011. Sarjana Kesehatan Kesehatan diperoleh dari STIKes Helvetia Medan pada Tahun 2014. Saat ini aktif sebagai pegawai pengajar Program Studi D-III Perekam Medis dan Informasi Kesehatan Universitas Imelda Medan 